\title{
ANL/XFD/CP-- 94495
}

\section{SILICON-TO-SILICON DIRECT BONDING AND ITS APPLICATION TO SYNCHROTRON X-RAY OPTICS* CONF-970706--}

T. Graber, ${ }^{\circ}$ S. Krasnicki, P.B. Fernandez, and D. M. Mills

Experimental Facilities Division

Advanced Photon Source, Argonne National Laboratory

Argonne, IL 60439

Q.-Y. Tong and U.M. Gösele

Wafer Bonding Laboratory, School of Engineering, Duke University, Durham, NC 27708

and

The Max-Plank Institute of Microstructure Physics, Halle, Germany

February 1997

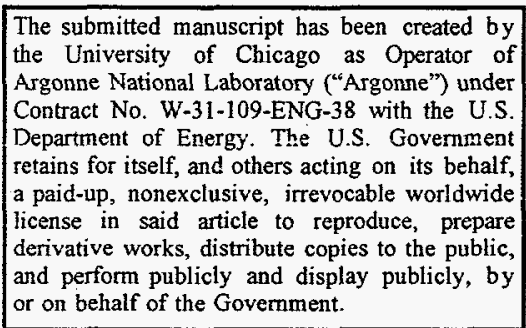

MASTER

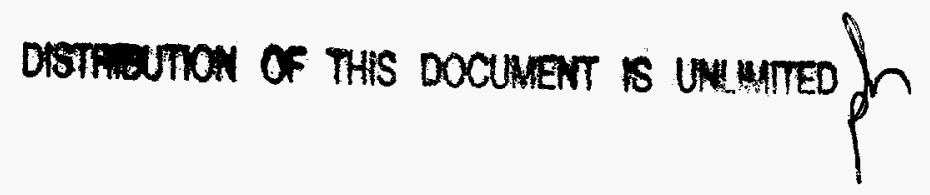

Manuscript presented at the SPIE 42nd Annual Mtg., Conference on High Heat Flux Engineering IV, San Diego, CA, July 27-August 1, 1997.

${ }^{\dagger}$ Present Address, The Center for Advanced Radiation Sources, University of Chicago, 5640 South Ellis Avenue, Chicago, IL 60637.

${ }^{*}$ This work is supported by the U.S. Department of Energy, Basic Energy Sciences-Materials Sciences, under contract \#W-31-109-ENG-38. 


\section{DISCLAIMER}

This report was prepared as an account of work sponsored by an agency of the United States Government. Neither the United States Government nor any agency thereof, nor any of their employees, make any warranty, express or implied, or assumes any legal liability or responsibility for the accuracy, completeness, or usefulness of any information, apparatus, product, or process disclosed, or represents that its use would not infringe privately owned rights. Reference herein to any specific commercial product, process, or service by trade name, trademark, manufacturer, or otherwise does not necessarily constitute or imply its endorsement, recommendation, or favoring by the United States Government or any agency thereof. The views and opinions of authors expressed herein do not necessarily state or reflect those of the United States Government or any agency thereof. 


\section{DISCLAMIER}

Portions of this document may be illegible in electronic image products. Images are produced from the best available original document. 


\title{
Progress in silicon-to-silicon direct bonding and its application to synchrotron $\mathrm{x}$-ray optics
}

\author{
T. Graber", S. Krasnicki, P. B. Fernandez, and D. M. Mills \\ Advanced Photon Source, Argonne National Laboratory, Argonne, IL 60439 \\ Q. -Y. Tong and U. M. Gösele \\ Wafer Bonding Laboratory, School of Engineering, \\ Duke University, Durham, North Carolina 27708 \\ and \\ The Max-Plank Institute of Microstructure Physics, Halle, Germany
}

\begin{abstract}
$\mathrm{X}$-ray optical elements (such as single-crystal silicon monochromators) illuminated with high-power synchrotron-radiation beams produced by insertion devices and, to a lesser extent bending magnets, require cooling. When operating a silicon crystal at room temperature, channels for the coolant are often fabricated directly beneath the diffracting surface. Then a separate silicon distribution manifold/plenum is manufactured, and the components are bonded together using an adhesive or some intermediate material. In many cases, such monochromators suffer from strains induced by the bond. A silicon-to-silicon direct-bonding technique (i.e., without any intermediate material) has been developed that appears to be an attractive method for creating a bond with less strain between two pieces of silicon. This technique is well understoed for the case of thin wafers $(\sim 0.5 \mathrm{~mm}$ thickness) and is used by the semiconductor industry. Recently, bonding of $16-\mathrm{mm}$ thick 10-cm-diameter silicon crystals has been successfully performed inducing very little strain. A short review of the silicon-to-silicon direct-bonding process will be presented with an emphasis on its application to room temperature high-heat-load $x$-ray optics along with the present status of direct bonding efforts at the APS.
\end{abstract}

Keywords: high-heat-flux optics, synchrotron radiation, silicon-to-silicon direct bonding, $\mathrm{x}$-ray monochromator

\section{Introduction}

The Advanced Photon Source (APS) at Argonne National Laboratory (ANL) is a third-generation, $x$ ray synchrotron source that produces beams with high spectral brilliance [1]. Along with this high brilliance also come high power and power density that must be effectively handled. It is not surprising that insertion device beams, with power densities of $160 \mathrm{~W} / \mathrm{mm}^{2}$ at the typical location of the first optical element, require carefully designed cooling schemes. At third-generation sources, such as the APS, even bending magnet radiation can produce thermal distortions in the first optical elements if they are not properly cooled. The heat absorbed in the first crystal of a double-crystal monochromator (DCM) can induce thermo-mechanical strains in the crystal degrading the monochromator performance by decreasing the brilliance of the diffracted beam. Hence, a comprehensive program in developing cooled $x$-ray optics at the APS was initiated early in the planning stages of the project to mitigate the loss of beam brilliance by thermally distorted optics. One of the many areas of development that were investigated was silicon-to-silicon bonding techniques for fabricating near-room-temperature, single-crystal-silicon monochromators.

\footnotetext{
" Present Address, The Center for Advanced Radiation Sources, University of Chicago, 5640 South Ellis Avenue, Chicago, IL 60637
} 
One approach to remove the heat from the diffracting surface of the first crystal in a DCM is to fabricate a system of channels (called a heat exchanger), through which liquid coolant can flow, close to the diffraction surface. Typically, directly cooled room-temperature single-crystal $\mathrm{x}$-ray optics consist of two or more machined silicon pieces bonded to each other and attached to a metal manifold. Figure 1 shows a typical arrangement for such a setup. A cooling fluid (we have investigated the use of both water [2] and liquid gallium [3]) flows in from the bottom, over the fins of the heat exchanger, and out through the exit port. The optimal thickness, length, and spacing of the fins that make up the heat exchanger, and hot face thickness (fin-to-diffraction-surface distance) depend strongly on the properties and flow velocity of the coolant used. Typical fin thickness and spacing are $1 \mathrm{~mm}$ with lengths of several millimeters. The hot face thickness is usually about $1 \mathrm{~mm}$. In most cases, the heat exchanger and the plenum are manufactured separately, etched, and bonded to produce a completed crystal optic. Just as in the case of thermo-induced strains, any distortion of the diffraction planes caused by the bonding process will reduce the brilliance of the diffracted beam. This process-induced strain is permanent and cannot be removed once the elements are bonded. Therefore, achieving strain-free, silicon-to-silicon bonds has been one of the goals of the high-heat-load (HHL) optics program at the APS. It is worth noting here that we have also developed other monochromator designs (in particular monolithic, liquid-nitrogen-cooled, single-crystal silicon monochromators) that eliminate the need for bonding [4]. However, such monochromators are more costly than their room-temperature counterparts and not necessary for typical bending-magnet-radiation heat loads.

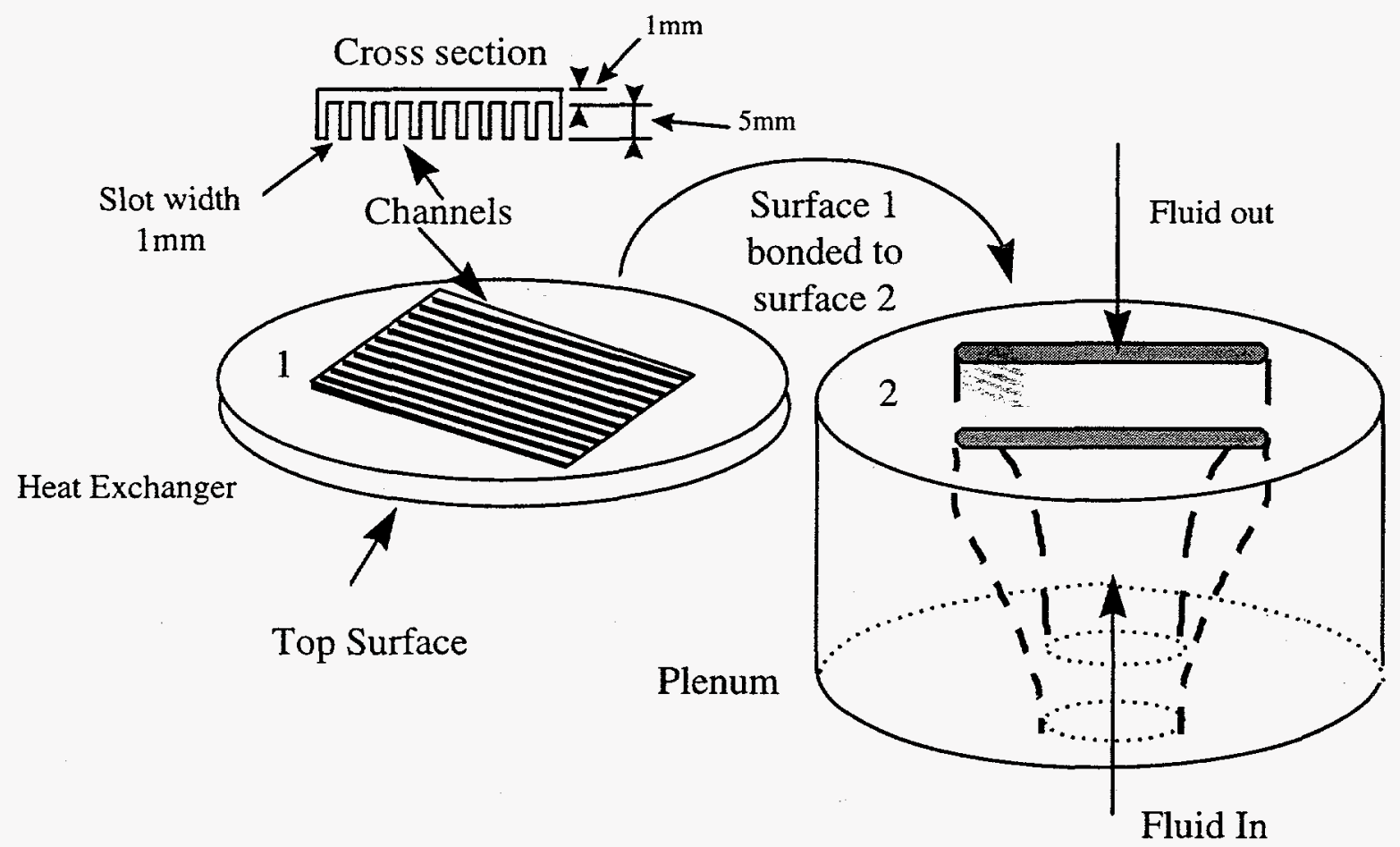

Figure 1. Layout of a typical high-heat-load crystal setup before bonding. The top layer (1) has a heat exchanger cut into it and will be bonded to the plenum surface (2).

A viable bond for a room-temperature, cooled silicon optic must be: (1) strain free, (2) compatible with the coolant used, (3) radiation resistant, (4) vacuum compatible, and (5) the coefficient of thermal expansion of the bonding agent must be close to that of silicon. Several adhesive-based bonding methods have been tested at the APS over the past few years with varying degrees of success. They include Si-Si dieattach-paste bonding, $\mathrm{Si}-\mathrm{Si}$ epoxy bonding, and $\mathrm{Si}$-Si glass-frit bonding. Although these techniques have produced strong bonds, they all have produced a residual strain in the crystal of several arc seconds after bonding. The outcome of these past tests will be briefly summarized in the next section. 
Silicon-to-silicon direct bonding (i.e., without any adhesives) appears to be an attractive method for creating a strain-free bond between two silicon crystals [5,6]. Recentiy, a silicon-to-silicon direct bonding program was undertaken at the APS in collaboration with The Wafer Bonding Laboratory at Duke University. The objective of this collaboration was to determine the feasibility of this technique for manufacturing $\mathrm{x}$-ray optics. The direct-bonding process has led to the development in other fields of new micromechanical devices, such as pressure sensors and accelerometers. In addition, it has also been used with success for manufacturing high-voltage bipolar transistors and high-voltage ultrafast rectifiers in the semiconductor industry $[7,8]$.

It is obvious that, of the five requirements listed previously for an acceptable silicon bond, silicon-tosilicon direct bonding will satisfy the last three to the extent that pure silicon satisfies these conditions. The first requirement, producing a strain-free bond, has been demonstrated for thick silicon crystals and will be discussed in section 3.3 of this paper. The purpose of this paper is to present a brief review of the APS silicon-to-silicon direct-bonding effort and compare the technique to previous bonding methods.

\section{Bonding Techniques Using Adhesives}

Several adhesive-type bonding techniques were tested previously at the APS. They included silverbased die-attach paste, epoxy, and glass-frit bonding. Some of the crystals bonded using these techniques were characterized by $x$-ray topographic methods, and the results are summarized below. All of the topographic investigations were performed at the APS, Experimental Facilities Division (XFD) topography station. For a complete review of this facility, see Krasnicki [9]. The adhesive-bonded crystals chosen for topographic testing were approximately of the type shown in Fig. 1, although they differed in thickness and the details of the heat exchanger and plenums.

Silver-based die-attach paste is a mixture of glass, silver, and organic compounds [10]. The silver in the glass paste serves several functions. It fills in any voids between the mating surfaces, enhances the electrical and thermal conductivity of the bond, and makes the coefficient of thermal expansion of the paste closer to that of silicon. Topographic measurements of a crystal bonded using this technique showed that the diffraction planes near the surface had a convex curvature. The strain induced in the crystal, measured over the entire 10-cm-diameter face with the $\mathrm{x}$-ray-beam direction oriented along the cooling channels, was 3.3 arc seconds.

Another in-house bonding technique that we have used employed epoxy [11]. This epoxy worked well, from an adherence point of view, for both silicon-to-silicon and silicon-to-metal bonds. The measured strain induced by the bonding process was 15.4 arc seconds. Because the strain induced in the crystal was quite large, it was concluded that this technique would not be suitable for manufacturing a high-heat-load $\mathrm{x}$ ray optic.

Figure 2 (a) demonstrates the rocking curve of a glass-frit-bonded crystal. The measured width in Fig. 2 (a) is 3.5 arc seconds, which indicates a strain of 2.9 arc seconds. Figure 2 (b) shows a topograph taken at the top of the rocking curve. In this case, the $\mathrm{x}$-ray beam was incident along the direction of the cooling channels. The white area of the topograph represents the part of the crystal surface diffracting $x$-rays at the rocking-curve peak. In this case the top-left and bottom-right of the crystal are slightly strained and do not contribute significantly to the measured $\mathrm{x}$-ray flux at this point in the rocking curve. The round black circle in the center of the topograph is caused by a hole in the center of the phosphor screen used to take the photo. This crystal was bonded by Boeing (formally Rockwell International) [12] and, when compared to the previous adhesive bonding attempts, showed the least bond-induced strain. 


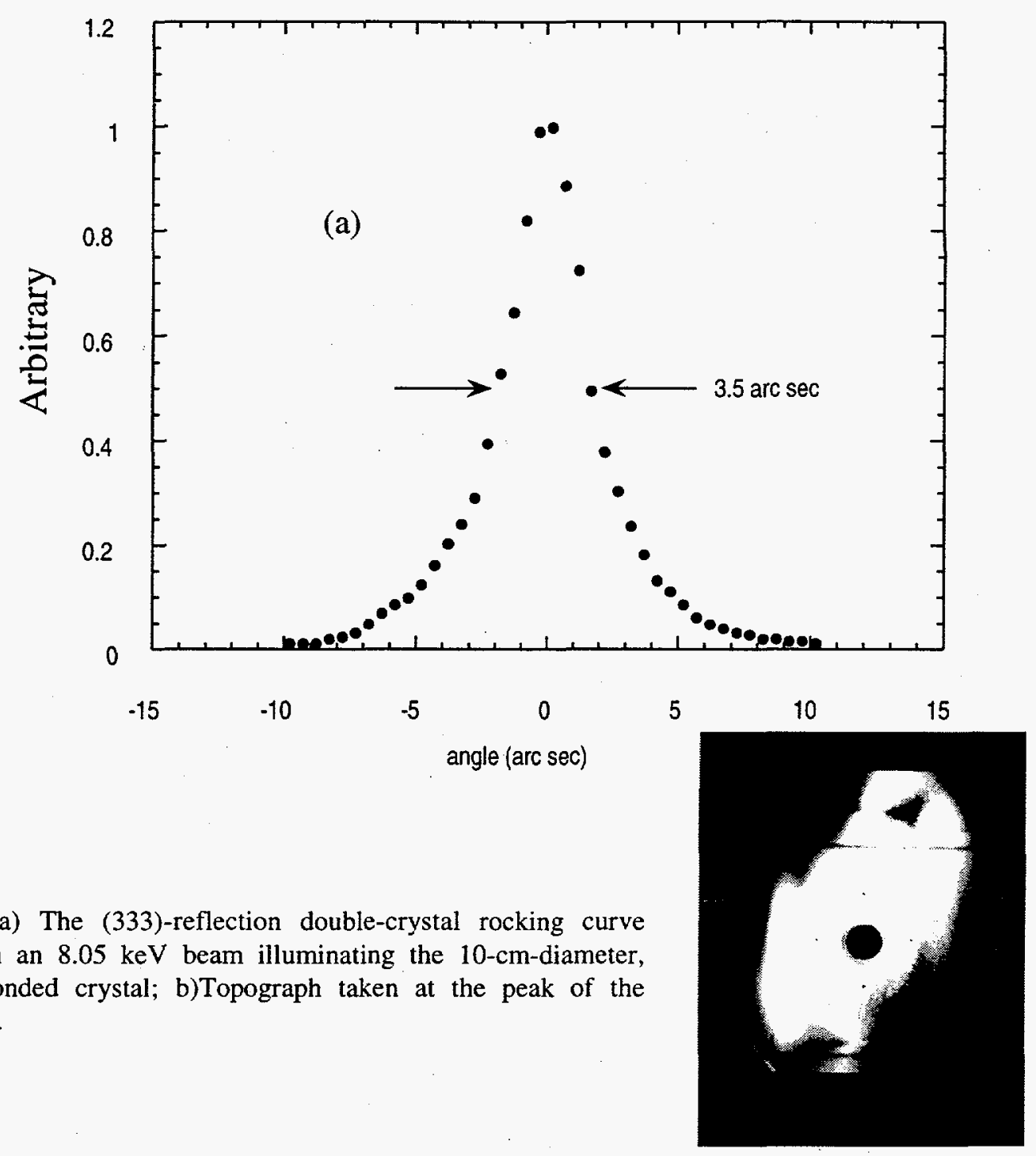

Figure 2. a) The (333)-reflection double-crystal rocking curve obtained with an $8.05 \mathrm{keV}$ beam illuminating the 10 -cm-diameter, slotted frit-bonded crystal; b)Topograph taken at the peak of the rocking curve.

\section{Silicon Direct Bonding}

\subsection{General Remarks}

Silicon-to-silicon direct wafer bonding has been the subject of considerable interest in both the academic and industrial communities for the past several years [7]. In its simplest form, it is a technology that allows one to bond two mirror-polished silicon wafers together without any intermediate material. Application of this technique to the manufacture of microelectronic devices has been widespread and has led to a reduction in manufacturing costs $[7,8]$. The recent extension of this technique from wafers (thickness $\sim 0.5 \mathrm{~mm}$ ) to relatively thick disks (thickness $\sim 16 \mathrm{~mm}$ ) of float-zone silicon [6] could lead to its application in the field of high-heat-load $x$-ray optics.

Direct bonding can be realized using several procedures (for example, see $[7,8]$ ). The particular procedure used at the APS, which is very similar to the one developed at Duke University, can be separated into four steps. (1) The cleaning and surface activation step: During this step the silicon surfaces to be bonded are made hydrophilic (attractive to water). Activation is caused by chemical treatment followed by washing the wafers in DI water. However, it should be pointed out that some wafers as supplied by manufacturers are, to some degree, hydrophilic without any treatment. (2) Final washing and drying: After activation, the wafers 
are spun at rates of up to $50 \mathrm{rpm}$ while being sprayed with high resistivity DI water. After the water is shut off, the rate is increased to $3000 \mathrm{rpm}$ and the wafers are heated by an infrared lamp. This last step removes any remaining water from the surfaces. (3) Forming primary bonds: Dried surfaces are mated in a clean dustfree environment and, if required, pressed together. (4) Forming final bond: In order to increase the bond strength, the composite is annealed in a furnace. Details of the $\mathrm{Si}-\mathrm{Si}$ direct bonding process can be found in references $[6,7,8]$.

\subsection{Thin Wafer Tests at the APS}

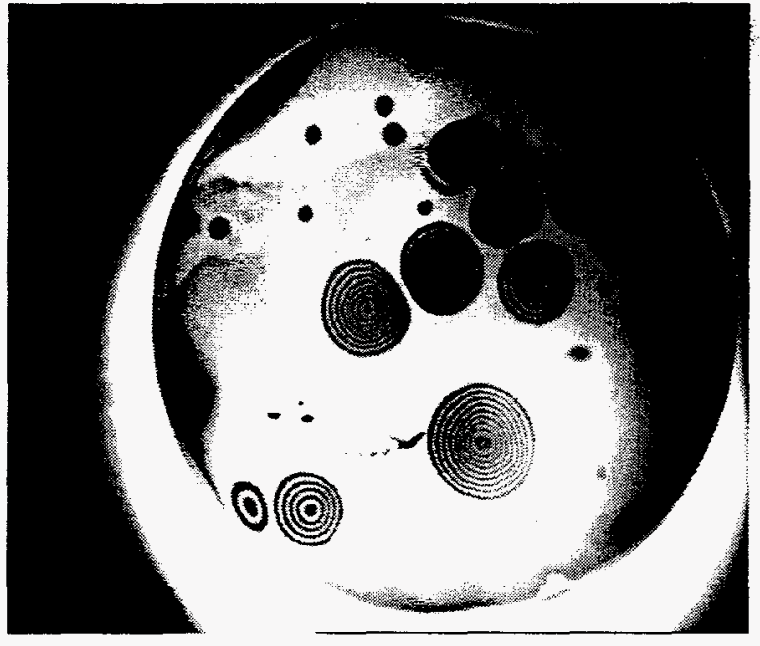

Figure 3. A bonded pair of thin silicon wafers with the bond interface contaminated with several large dust particles.
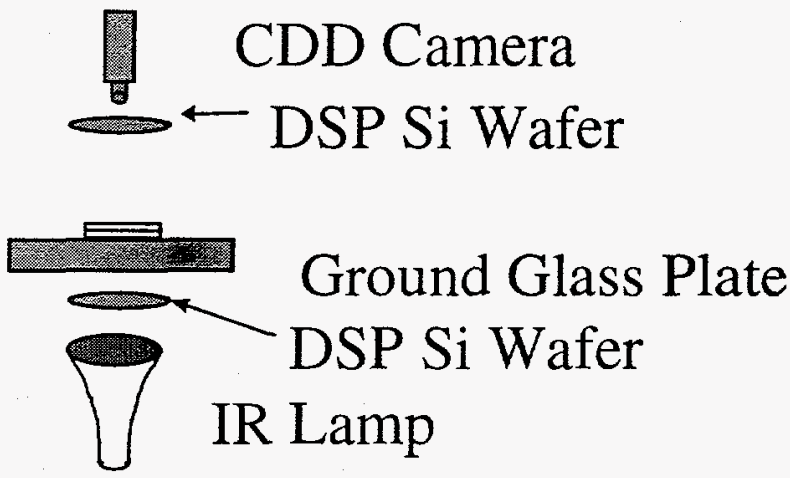

Figure 4. The IR imaging system used for inspecting the bonded interfaces was constructed using a conventional CCD camera rather than a more expensive IR camera system. See text for details.
In order to determine the feasibility of the direct bonding technique for manufacturing HHL monochromator crystals, tests were performed on thin ( $t \sim 0.5$ $\mathrm{mm}$ ) silicon wafers to perfect the technique in house, while a simultaneous program on bonding relatively thick silicon crystals was carried out in collaboration with Duke University.

Figure 3 shows the result of one of the first direct bonding attempts at the APS. This is an IR transmission photograph of two directly bonded wafers. The surfaces of the wafers shown in Fig. 3 were prepared in the following way [13]: the wafers were placed in an RCAl $\left\{\mathrm{NH}_{4} \mathrm{OH}-\mathrm{H}_{2} \mathrm{O}_{2}-\mathrm{H}_{2} \mathrm{O}\right.$ $(1: 1: 5)\}$ bath at $80^{\circ} \mathrm{C}$ for 15 minutes. Then the wafers were placed in a flowing DI water bath for 10 minutes. The resistivity of the water was held at $16-18 \mathrm{M} \Omega-\mathrm{cm}$ for the duration of the bath. Next, the wafers were placed in an RCA2 \{HCL- $\mathrm{H}_{2} \mathrm{O}_{2}-\mathrm{H}_{2} \mathrm{O}$ $(1: 1: 6)\}$ bath at $80^{\circ} \mathrm{C}$ for 15 minutes and again immersed in running DI water for 10 minutes. The RCA1 clean is conventionally used to remove organic contaminants from the surface of the wafer. However, for direct bonding it is also used to make the surfaces hydrophilic. The RCA2 clean is used to remove heavy metals from the surface of the wafer.

After mating, the wafer pair was annealed at $1100^{\circ} \mathrm{C}$ for two hours. The furnace was ramped up to $1100^{\circ} \mathrm{C}$ and later cooled down at the rate of $5 \% \mathrm{~min}$. The bond was so strong after annealing, that the wafers could not be separated.

Bonded wafer pairs (see Fig. 3) were inspected using the setup shown in Fig. 4. A standard CCD camera, which has wavelength sensitivity up to about $1 \mu \mathrm{m}$, is used to record the image. The upper doublesided mirror-polished (DSP) silicon wafer acts like a filter cutting out visible light while letting the IR light pass into the 
camera. Beneath the ground glass plate, on which the bonded wafer is resting, is a DSP silicon wafer that reduces any heating of the ground glass plate by the IR lamp.

The rings clearly seen in Fig. 3 are caused by voids at the bond interface. When viewed with the IR camera setup, these voids appear as interference patterns caused by the well-known "Newton's rings" effect. For near normal incidence viewing, the height $h$ of a void is given by

$$
h \approx \frac{m \lambda_{o}}{2 n} \text {, }
$$

where $\mathrm{m}$ is the number of rings; $\lambda_{\mathrm{o}}$ is the wavelength of the transmitted light; and $\mathrm{n}$ is the index of refraction of the material inside the void. For a typical void in Fig. 3, the estimated height is $\sim 2 \mu \mathrm{m}$. One of the most prominent features of Fig. 3 is the large number of voids present at the interface. These voids are primarily due to large dust particles. A typical size for a dust particle is about 1 to $2 \mu \mathrm{m}$.

In order to alleviate the problem of dust collecting at the bonding interface, a minienvironment cleanroom was set up and is shown in Fig. 5. The enclosure is a modified standard glove box purchased from Contamination Control \& Devices, Inc. [14]. The top of the box has been fitted with a HEPA filter (which eliminates particles with a diameter greater than 0.3 microns) and a blower delivering $200 \mathrm{cfm}$. With the HEPA filter, this setup should provide a class 100 clean room environment. The bottom of the glove box was cut out, and a stainless steel grate was installed. This provided an air flow pattern that is mostly laminar.

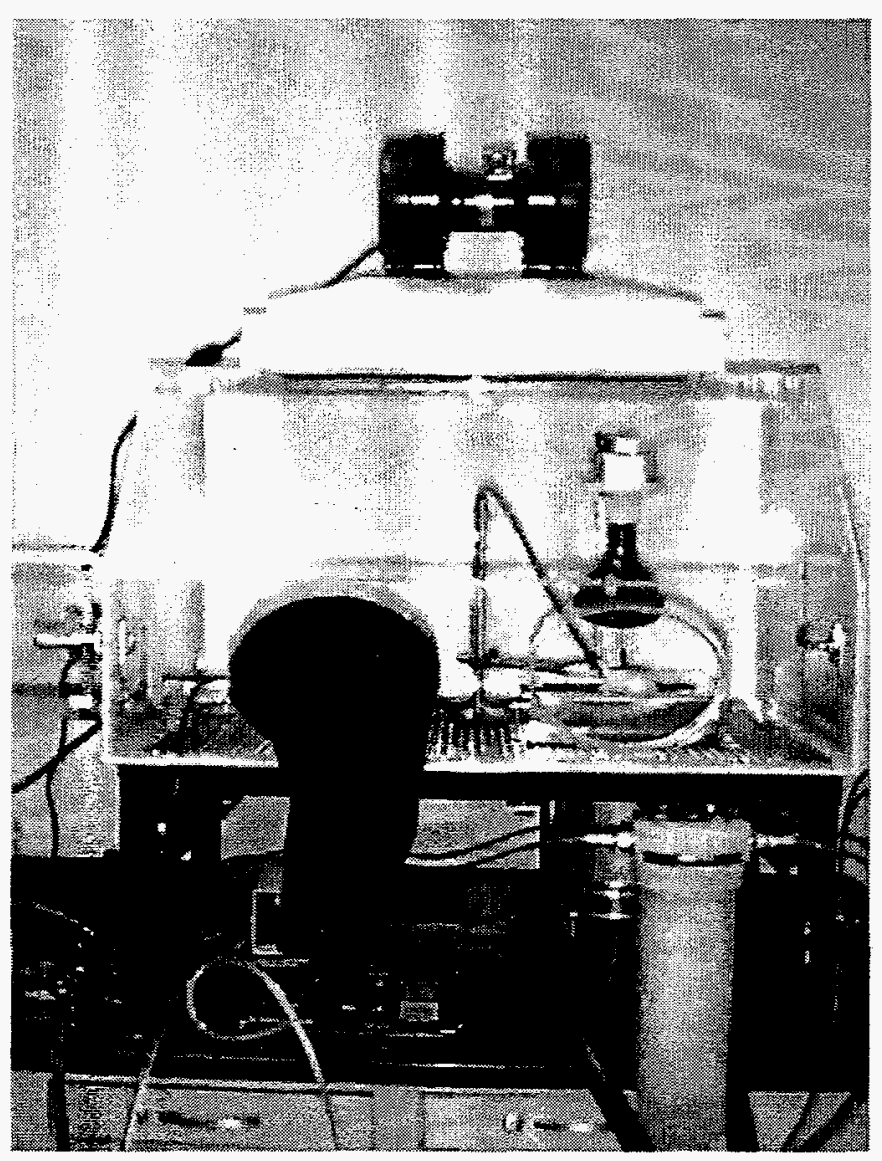

In the setup shown in Fig 5, a glove has been removed so that the reader can get a clear view of the spinner, a nozzle to spray DI water on the wafer while it is spinning, and the IR lamp used to dry the surface of the silicon after the DI water has been shut off. Before bonding, the entire box is sprayed to remove any residual dust, with an ionizing blow off gun, which delivers a clean dust-free stream of ionized dry nitrogen. A transfer box was also added on the left side so that bonding tools and silicon pieces to be bonded could be inserted into the box introducing minimal dust contamination.

Images of bonded wafers, after spin drying with the IR lamp at $3000 \mathrm{rpm}$ and annealing at $1100^{\circ} \mathrm{C}$, are shown in Fig. 6 . The spin times of $2,4,5$, and 8 minutes were chosen. Voids can clearly be seen on all but the 5 minute run with the 8 minute run being the worst. Therefore, it was concluded that, for this particular IR-lampto-wafer distance, a 5 minute spin/heat time was optimal.

Figure 5. Bonding setup. Right glove removed to show the spinner, DI water nozzle, and IR lamp. 
2 minutes

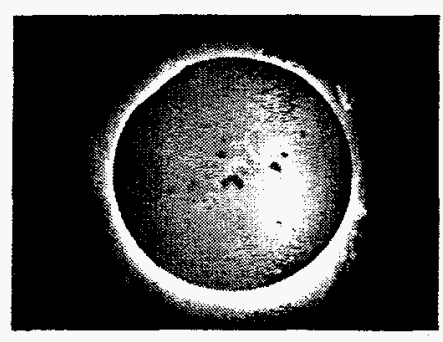

5 minutes

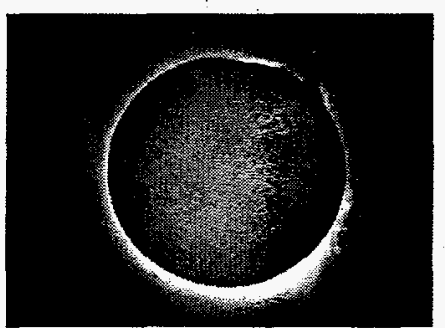

4 minutes

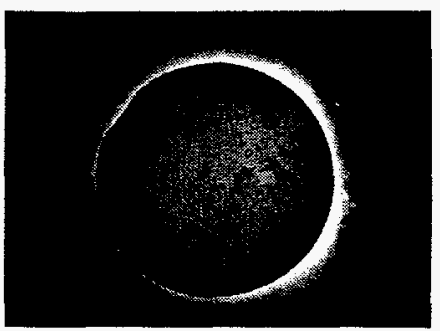

8 minutes

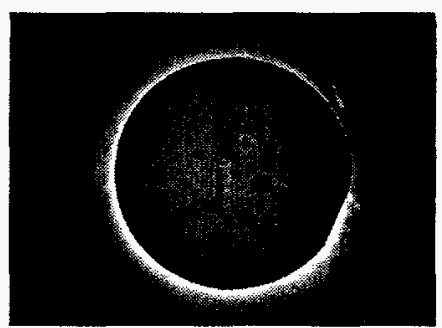

Figure 6. IR images of four directly bonded wafers shown as a function of drying time. See text for details.

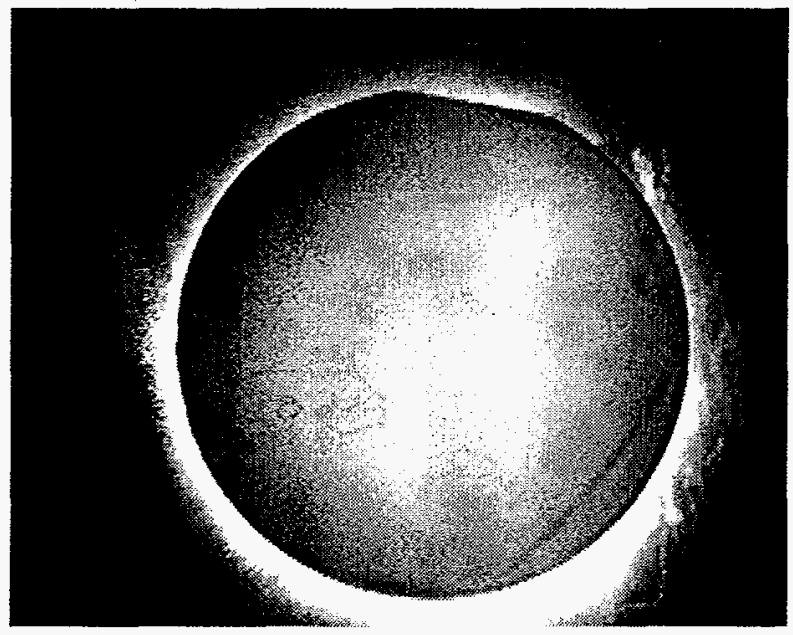

Figure 7. IR image of the best set of wafers bonded at APS to date

Fig. 7 shows an IR photograph of the first "void free" directly bonded wafer produced at the APS. It is worth noting that the wafers used for this bonding were not cleaned with the RCA1 and RCA2 processes. After being taken directly from the box, the wafers were sprayed with DI water while spinning at a rate of $3000 \mathrm{rpm}$. Evidently, the cleaning procedure used by the manufacturer was sufficient to make the surfaces hydrophilic. 


\subsection{Thick Crystal Bonding}

The thickness of both crystals is an important consideration when attempting a direct bond. When a pair of wafers bonds at room temperature, the force is primarily of van der Waals type. This is a short range force, which puts an upper limit of about $\sim 5 \AA$ on the microroughness of the wafers. The flatness of thin ( $t \sim$ $0.5 \mathrm{~mm}$ ) wafers is not so critical because the wafers deform during the bonding process and "fit" to each other. A slight warping in one of the wafers can be overcome by the force of the bond. However, for thick crystals, Tong and Gösele. [15] found that main requirement for achieving a direct bond is the flatness of the crystal surface. For instance, a crystal as thick as $16 \mathrm{~mm}$ must have a surface flatness of about $\lambda / 10$ $(\lambda \sim 630 \mathrm{~nm})$.

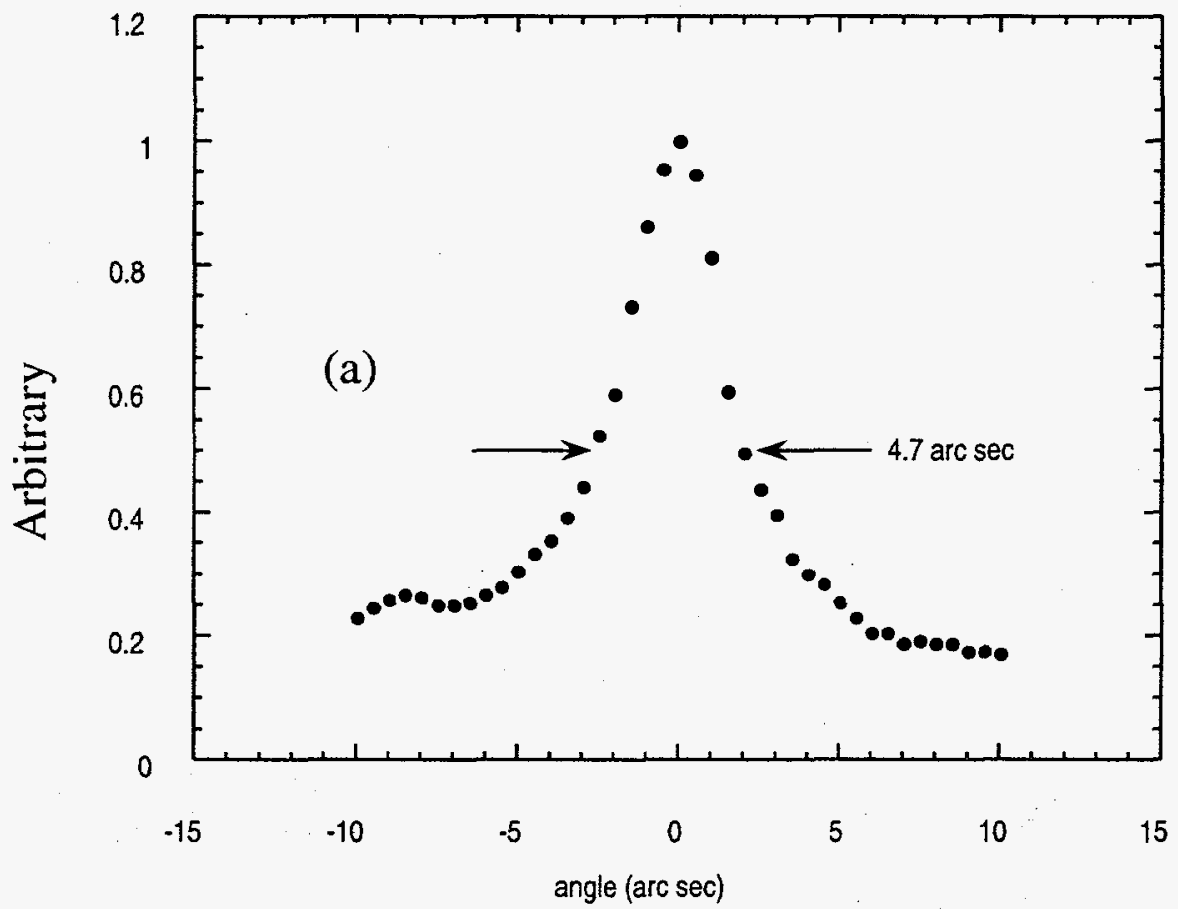

Figure 8. Topographic data on the $10-\mathrm{cm}-$ diameter, 2-mm-thick, directly bonded silicon wafers: a) Double-crystal (333) rocking curve with the full face of the crystal illuminated by the $8.05 \mathrm{keV}$ x-ray beam. b) Superposition of topographs taken at several points (in 4 arc seconds steps ) of the rocking curve.

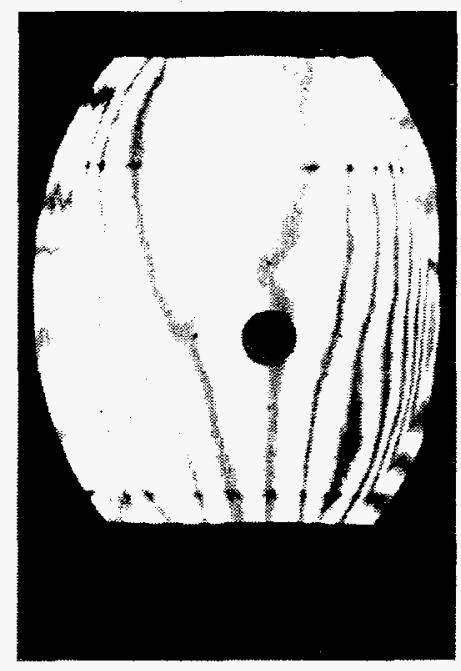

(b) 
As a first attempt at bonding thick crystals $(>0.5 \mathrm{~mm}$ ), two 10-cm-diameter, 2-mm-thick silicon wafers were bonded at Duke University utilizing a cleaning procedure similar to the one used at the APS. The bonded assembly has been examined with the topography unit (see Fig. 8). The 4.7 arc second width of the rocking curve corresponds to a strain of 4.3 arc seconds (quadrature subtraction of 2.0 arcsec theoretical width). The topographs suggested an overall bending/convex shape of the bonded assembly, with a reasonably flat central region responsible for the wide reflecting band in the center of Fig. 8 (b). It was concluded that these crystals were probably warped during the bonding process. Because most monochromator designs require a crystal thickness of at least $6 \mathrm{~mm}$ for the heat exchanger and at least $16 \mathrm{~mm}$ for the plenum, it was essential to proceed with bonding of relatively thick $(16 \mathrm{~mm})$ silicon crystals.

Two 16-mm-thick silicon slabs originating from the adjacent layers of the same ingot were prepared (cut, lapped and etched) at the APS and sent to Janos Technology, Inc., for final polishing. Faces assigned for bonding were to be polished flat (within $63 \mathrm{~nm}$ over a $10 \mathrm{~cm}$ diameter) and optically smooth. After polishing, the crystals were checked in the APS metrology lab (flatness and roughness) and by x-ray topography. The polished faces exhibited a peak-to-valley flatness of $0.13 \lambda(\lambda=632.8 \mathrm{~nm})$ and $0.1 \lambda$ and an RMS roughness of $0.46 \mathrm{~nm}$ and $0.49 \mathrm{~nm}$. The widths of (333) rocking curves for the polished faces, where the most damage to the crystal is likely to occur, were 2.4 arcsec and 2.8 arcsec. It should be stressed, that these faces will be

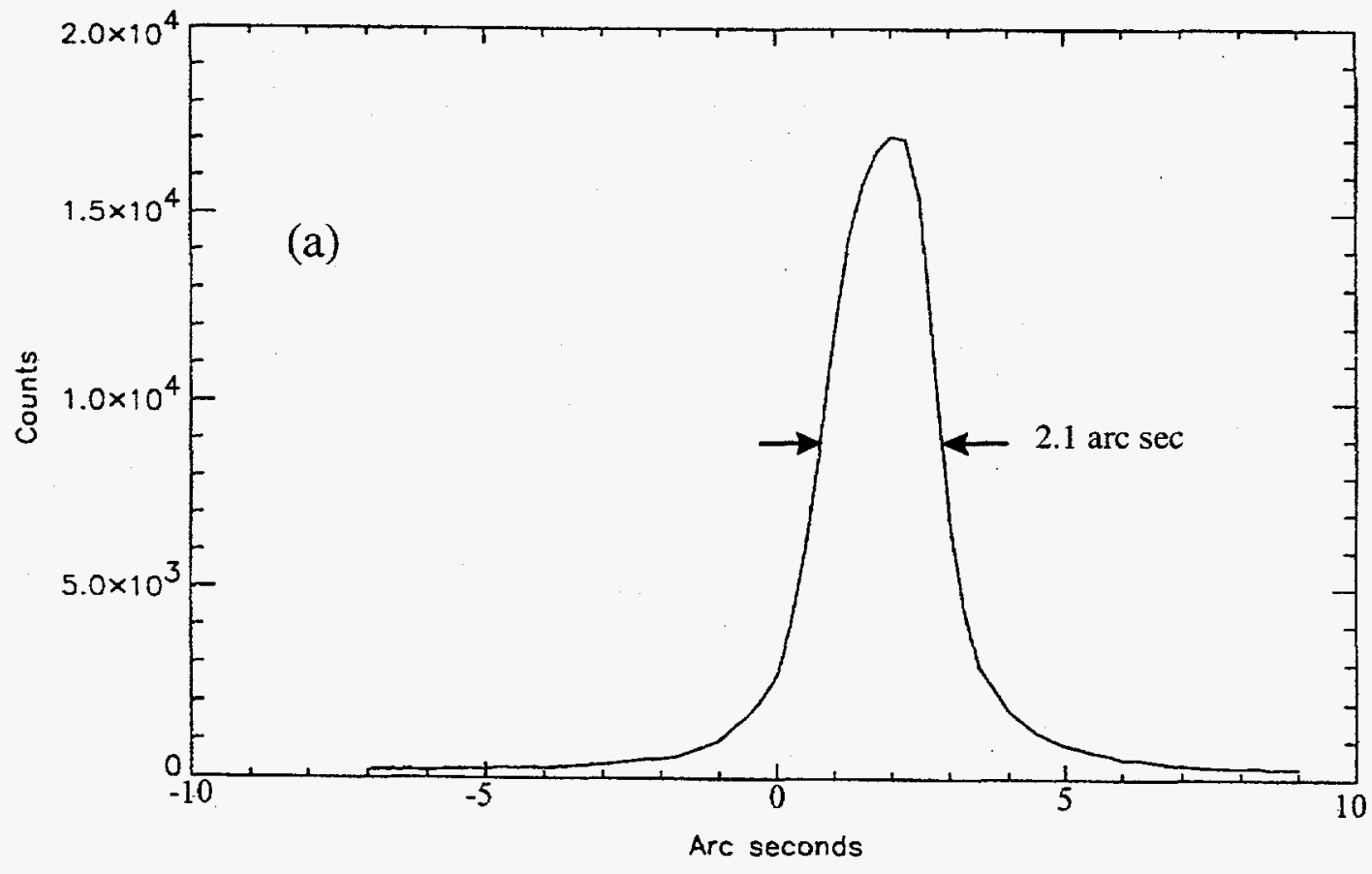

Figure 9. Topographic data on the $10-\mathrm{cm}$ diameter, 16-mm-thick, directly bonded silicon crystal: a) Double-crystal (333) rocking curve measured using $8.05 \mathrm{keV} x$-rays with a beam cross section of $2.5 \times 2.5 \mathrm{~cm}^{2}$; FWHM 2.1 arc sec. b) Topograph of the entire crystal surface taken at the peak of the rocking curve.

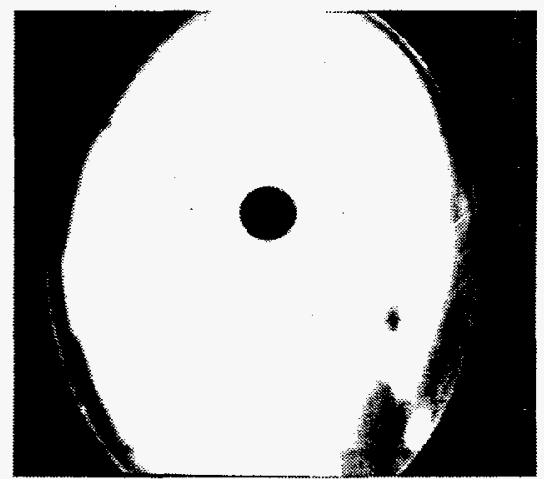

(b) 
bonded together and are not the diffraction surfaces.

The slabs were successfully bonded and were reexamined using x-ray topography at the APS. The topographic measurements were performed at distances of $16 \mathrm{~mm}, 6 \mathrm{~mm}$ and $2.4 \mathrm{~mm}$ from the bond plane. Experiments at $6 \mathrm{~mm}$ and $2.4 \mathrm{~mm}$ were carried out after cutting out appropriate silicon layers from one of the original 16-mm-thick constituent slabs. The rocking-curve widths for the (333) reflection measured using $8.05 \mathrm{keV}$ radiation at all three distances from the bond plane were similar; about 2.5 arc sec for the full 10$\mathrm{cm}$-diameter surface, and between 2.1 arc sec to 2.2 arc sec for the central part of the crystal. Some topographic results obtained for the surface $2.4 \mathrm{~mm}$ distant from the bond plane are shown in Fig. 9 .

\section{Conclusions and Future Work}

Although cryogenically cooled silicon crystals, which can be fabricated with no bonding, have been shown to function very well even under the influence of the high power density undulator beams, bonded silicon crystals may still have an important application for room temperature optics. One application is for bending magnet sources, in which case one has a relatively low power density but still needs to remove many hundreds of watts of power. The bending magnet sources at the APS produce 86 watts/horizontal-mrad with $100 \mathrm{~mA}$ of stored beam. With a horizontal acceptance of 6 mrads for the bending magnet front ends, this corresponds to a total power of over 500 watts that could strike the first optical component. With even higher currents projected in the near future, bonded crystals may be the most appropriate choice for this application.

Of the three adhesive bonding techniques discussed in section 2 , glass-frit bonding proved to be superior to both epoxy and the die-attach-paste bonding. It induced a strain of only 2.9 arc seconds over the entire crystal. In the topograph of the frit-bonded crystal shown in Fig. 2 (b), almost the entire surface of the crystal is diffracting at the peak of the rocking curve. If silicon-to-silicon direct bonding is to be a useful technique for bonding high-heat-load $\mathrm{x}$-ray optics, it must be competitive with or superior to glass-frit bonding.

Silicon-to-silicon direct bonding may be the best method for strain-free bonding of silicon monochromator crystals. However, there are still some problems to overcome. Manufacturing a strain-free heat exchanger and preparation of the surfaces to be bonded (especially for large and irregular pieces of silicon) still pose significant difficulties.

Table 1 gives a comparison of rocking curve widths and strains induced for the various bonding methods described in this paper. Direct bonding led to the least strain induced in the crystal due to the manufacturing process. It should be pointed out that the comparison is not exact, because the directly bonded crystal did not have a heat exchanger manufactured into it.

Table 1. Comparison of the rocking-curve FWHM [Si (333) $8.05 \mathrm{keV}$ ] and bonding strains induced for several methods. The direct-bonded-crystal rocking curve was taken over the entire crystal face.

\begin{tabular}{|c|c|c|c|c|}
\hline Bonding Method & Die Attach Paste & Epoxy & Glass Frit & Direct $(1.6 \mathrm{~cm})$ \\
\hline FWHM $(\operatorname{arcsec})$ & 3.9 & 15.5 & 3.5 & 2.5 \\
Strain $(\operatorname{arcsec})$ & 3.3 & 15.4 & 2.9 & 1.5 \\
\hline
\end{tabular}

Recently, experiments were performed on direct bonding of slotted/drilled slabs similar to the one shown in Fig. 1. The results are very preliminary. It was concluded that the direct bond between the $1-\mathrm{mm}-$ wide ribs and the top surface of the plenum does work well and that the upper limit of the width of the (333) reflection $1 \mathrm{~mm}$ from the surface above the bottom of the channels is about $3.5 \mathrm{arc} \mathrm{sec}$. Further experiments are in progress.

\section{Acknowledgment}

This work was supported by the U. S. DoE under contract number W-31-109-Eng-38. The authors would like to thank Dr. Robert K. Smither, Dr. Albert Macrander, and Dr. Wah -Keat Lee for their help and suggestions. We would also like to acknowledge the assistance of Mr. Algirdas Paugys and Mr. Ronald Hopf. 


\section{References}

[1] "The Advanced Photon Source List of Parameters," Argonne National Laboratory Report, ANL/APS/TB26, July 1996.

[2] W. K. Lee, P.B. Fernandez, T. Graber, and L. Assoufid, "High-heat-load Synchrotron Tests of RoomTemperature Silicon Crystal Monochromators at the CHESS F-2 Wiggler Station," ANL Report LS-250 1995.

[3] R. K. Smither, W. K. Lee, A. T. Macrander, D. M. Mills, and C. S. Rogers, Rev. Sci. Instrum. 63, 1746, 1992.

[4] C. S. Rogers, D. M. Mills, W. K. Lee, P. B. Fernandez, and T. Graber, in High Heat Flux Engineering III, A. M. Khounsary, ed. SPIE Proceedings Vol. 2885, Denver, CO, August 1996.

[5] A. T. Macrander, M. Saginuri, S. Yao, P. J. Hesketh, and C. J. Bresloff, Rev. Sci. Instrum. 67 (9), 1996 CD ROM.

[6] Q.-Y. Tong, S. Krasnicki and U. Gösele, Proc. of the Third International Symposium on Semiconductor Wafer Bonding, May 21-26, 1995.

[7] Kiyoshi Mitani and Ulrich M. Gösele, Journal of Electronic Materials, Vol.21, No. 7, 699, 1992.

[8] D. L. Hughes, Proc. of the Second International Symposium on Semiconductor Wafer Bonding. Science Technology and Applications, Vol. 93-29, 17-31, 1993.

[9] Szczesny Krasnicki, Rev. Sci. Instrum. 67 (9), 1996 CD ROM.

[10] The die-attach paste used is Johnson Matthey JM 4613 AuSub ${ }^{\circledR}$ Die Attach Paste.

[11] The epoxy used is 3M Scotch-weld $1838 \mathrm{~B} / \mathrm{A}$ green epoxy.

[12] Boeing Corporation, $2511 \mathrm{C}$ Broadbent Parkway, Albuquerque, New Mexico 87101, Contact: Tom Tonnessen.

[13] W. Kern and D. A. Puotinen, RCA Review, 187,1970.

[14] Contanimation Control \& Devices, Inc., 510 Market Loop, West Dundee, IL 60118, Contact: Edward J. Hacket (708)428-5105.

[15]Q. -Y. Tong and U. Gösele, J. Electrochem. Soc., Vol. 142, No. 11, 3975, 1995. 